\title{
Intracellular Hydrogen Peroxide Produced by 6- Hydroxydopamine is a Trigger for Nigral Dopaminergic Degeneration Via Rapid Influx of Extracellular $\mathrm{Zn}^{2+}$
}

Ryusuke Nishio

University of Shizuoka

Hiroki Morioka

University of Shizuoka

Azusa Takeuchi

University of Shizuoka

Nana Saeki

University of Shizuoka

Ryo Furuhata

University of Shizuoka

Takato Chinenn

University of Shizuoka

Haruna Tamura

University of Shizuoka

Haruna Tamano

University of Shizuoka

Atsushi Takeda ( $\nabla$ takedaa@u-shizuoka-ken.ac.jp )

University of Shizuoka https://orcid.org/0000-0001-7519-2957

\section{Research Article}

Keywords: hydrogen peroxide, TRPM2 cation channel, Zn2+, dopaminergic neuron, substantia nigra, 6OHDA, Parkinson's disease

Posted Date: May 21st, 2021

DOl: https://doi.org/10.21203/rs.3.rs-512285/v1

License: (1) This work is licensed under a Creative Commons Attribution 4.0 International License. Read Full License 


\section{Abstract}

To elucidate the mechanism of 6-hydroxydopamine (6-OHDA)-induced $\mathrm{Zn}^{2+}$ toxicity, which is involved in neurodegeneration in the substantia nigra pars compacta (SNpc) of rats, we postulated that intracellular hydrogen peroxide $\left(\mathrm{H}_{2} \mathrm{O}_{2}\right)$ produced by $6-\mathrm{OHDA}$ is a trigger for intracellular $\mathrm{Zn}^{2+}$ dysregulation in the SNpc. Intracellular $\mathrm{H}_{2} \mathrm{O}_{2}$ level in the $\mathrm{SNpc}$ elevated by 6-OHDA was completely inhibited by co-injection of GBR 13069 dihydrochloride (GBR), a dopamine reuptake inhibitor, suggesting that 6-OHDA taken up through dopamine transporters produces $\mathrm{H}_{2} \mathrm{O}_{2}$ in the intercellular compartment of dopaminergic neurons. When the SNpc was perfused with $\mathrm{H}_{2} \mathrm{O}_{2}, \mathrm{H}_{2} \mathrm{O}_{2}$ accumulated glutamate in the extracellular compartment and the accumulation was inhibited in the presence of $\mathrm{N}$-(p-amylcinnamoyl)anthranilic acid (ACA), a blocker of the transient receptor potential melastatin 2 (TRPM2) channels. In addition to 6-OHDA, $\mathrm{H}_{2} \mathrm{O}_{2}$ also induced intracellular $\mathrm{Zn}^{2+}$ dysregulation via AMPA receptor activation followed by nigral dopaminergic degeneration. Furthermore, 6-OHDA-induced nigral dopaminergic degeneration was completely inhibited by co-injection of HYDROP, an intracellular $\mathrm{H}_{2} \mathrm{O}_{2}$ scavenger or GBR into the SNpc. The present study indicates that $\mathrm{H}_{2} \mathrm{O}_{2}$ is produced by 6-OHDA taken up through dopamine transporters in the $\mathrm{SNpc}$, is retrogradely transported to presynaptic glutamatergic terminals, activates TRPM2 channels, accumulates glutamate in the extracellular compartment, and induces intracellular $\mathrm{Zn}^{2+}$ dysregulation via AMPA receptor activation, resulting in nigral dopaminergic degeneration. It is likely that intracellular $\mathrm{H}_{2} \mathrm{O}_{2}$, but not extracellular $\mathrm{H}_{2} \mathrm{O}_{2}$, is a key trigger for nigral dopaminergic degeneration via intracellular $\mathrm{Zn}^{2+}$ dysregulation.

\section{Introduction}

The substantia nigra pars compacta (SNpc), a mesencephalic nucleus of the basal ganglia, serves in the regulation of voluntary movement. In Parkinson's disease (PD), dopaminergic neurons are selectively damaged and degenerated, resulting in progressive motor dysfunction symptoms, e.g., resting tremor, bradykinesia, rigidity, and postural imbalance [1]. Most PD patients are sporadic and aging is the major risk factor $[2,3]$. The exact mechanism of PD pathogenesis remains unclear, while oxidative stress hypothesis is well known as the pathogenetic mechanism. The SNpc is enriched with dopamine, which can undergo both enzymatic oxidation via monoamine oxidase and nonenzymatic autoxidation, resulting in the generation of hydrogen peroxide $\left(\mathrm{H}_{2} \mathrm{O}_{2}\right)$ and oxyradicals (superoxide anion radical and hydroxyl radical) in the SNpc [4].

6-Hydroxydopamine (6-OHDA) has been used to prepare a classic animal model of PD [5]. Reactive oxygen species (ROS) derived from 6-OHDA, which is taken up through dopamine transporters, intraneuronal 6-OHDA autoxidation, extracellular 6-OHDA autoxidation, and microglial activation are known as the mechanisms responsible for 6-OHDA-induced dopaminergic degeneration [6]. 6-OHDA is readily oxidized and generates a number of reactive and cytotoxic products, e.g., quinones, $\mathrm{H}_{2} \mathrm{O}_{2}, 5,6$ dihydroxyindole, the superoxide anion radical, the hydroxy radical, and singlet oxygen [7]. In the SNpc, 
presynaptic activity (glutamate exocytosis) after exposure to paraquat (1,1'-dimethyl-4,4'-bipyridinium dichloride, $\mathrm{PQ}$ ), a herbicide which is also taken up through dopamine transporters, is inhibited in the presence of $\mathrm{N}$-(pamylcinnamoyl)anthranilic acid (ACA), a blocker of the transient receptor potential melastatin 2 (TRPM2) cation channels, suggesting that ROS derived from PQ leads to glutamate exocytosis via TRPM2 channel activation in the SNpc, followed by nigral dopaminergic degeneration via intracellular $\mathrm{Zn}^{2+}$ dysregulation [8, 9].

Among intracellular ROS derived from 6-OHDA and $\mathrm{PQ}, \mathrm{H}_{2} \mathrm{O}_{2}$ readily passes through cell membranes through aquaporin channels $[10,11]$ and the elevation in the extracellular compartment can excites glutamatergic neuron terminals via TRPM2 channel activation [12-14], which innervates dopaminergic neurons in the SNpc. To elucidate the mechanism of 6-OHDA-induced $\mathrm{Zn}^{2+}$ toxicity, which is involved in dopaminergic degeneration in the SNpc of rats, we postulated that intracellular $\mathrm{H}_{2} \mathrm{O}_{2}$ produced by 6OHDA is a trigger for intracellular $\mathrm{Zn}^{2+}$ dysregulation in the SNpc. We examined an idea that 6-OHDA taken up through dopamine transporters produces $\mathrm{H}_{2} \mathrm{O}_{2}$ and that toxic signal of $\mathrm{H}_{2} \mathrm{O}_{2}$ is readily converted into that of $\mathrm{Zn}^{2+}$.

\section{Materials And Methods}

\section{Animals and chemicals}

Wistar rats (male, 10-20 weeks of age) were obtained from Japan SLC (Hamamatsu, Japan). They were housed under the standard laboratory conditions $\left(23 \pm 1^{\circ} \mathrm{C}, 55 \pm 5 \%\right.$ humidity) and had access to water and food ad libitum. The present experiments were done in accordance with the Guidelines for the Care and Use of Laboratory Animals of the University of Shizuoka, which refer to American Association for Laboratory Animals Science and the guidelines laid down by the NIH (NIH Guide for the Care and Use of Laboratory Animals) in the USA. All experimental protocols were approved by the ethics committee of the University of Shizuoka.

ZnAF-2DA, a membrane-permeable $\mathrm{Zn}^{2+}$ fluorescence probe (Sekisui Medical Co., LTD, Hachimantai, Japan) is readily taken up into the cells through the cell membrane and is hydrolyzed by esterase in the cytosolic compartment, resulting in generation of ZnAF-2 [15]. Intracellular ZnAF-2, which cannot permeate the cell membrane, is selectively bound to $\mathrm{Zn}^{2+}$, but not bound to other divalent cations such as $\mathrm{Ca}^{2+}, \mathrm{Mg}^{2+}, \mathrm{Fe}^{2+}$, and $\mathrm{Cu}^{2+}$. The indicator was dissolved in dimethyl sulfoxide and then diluted to Ringer solution containing $119 \mathrm{mM} \mathrm{NaCl}, 2.5 \mathrm{mM} \mathrm{KCl}, 1.3 \mathrm{mM} \mathrm{MgSO}_{4}, 1.0 \mathrm{mM} \mathrm{NaH}_{2} \mathrm{PO}_{4}, 2.5 \mathrm{mM} \mathrm{CaCl}_{2}, 26.2$

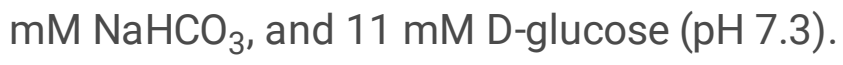

HYDROP $^{T M}$, a membrane-permeable $\mathrm{H}_{2} \mathrm{O}_{2}$ fluorescence probe (Goryochemical, Sapporo, Japan) is taken up into the cells through the cell membrane and is hydrolyzed in the cytosolic compartment, resulting in generation of HYDROP-EX, which cannot permeate the cell membrane [16]. HYDROP ${ }^{\text {TM }}$ is selectively 
bound to $\mathrm{H}_{2} \mathrm{O}_{2}$, but not bound to other ROS such as ${ }^{\square} \mathrm{OH}, \mathrm{O}^{2-\nabla}, \mathrm{ClO}^{\square},{ }^{1} \mathrm{O}_{2},{ }^{\square} \mathrm{NO}$, and $\mathrm{ONOO}$. The indicator was dissolved in $\mathrm{N}, \mathrm{N}$-dimethylformamide (DMF) and then diluted to Ringer solution.

\section{Surgical Operation}

The rats were anesthetized by intraperitoneal injection with chloral hydrate $(400 \mathrm{mg} / \mathrm{kg}$ ) and individually placed in a stereotaxic apparatus. After the skull was exposed, a burr hole was drilled and an injection cannula (internal diameter, $0.15 \mathrm{~mm}$; outer diameter, $0.35 \mathrm{~mm}$ ) was carefully and slowly inserted into the right SNpc (5.3mm posterior to the bregma, $2.0 \mathrm{~mm}$ lateral, $7.0 \mathrm{~mm}$ inferior to the dura) to prevent cellular damages. Thirty minutes after the surgical operation, $800 \mu \mathrm{M}$ 6-OHDA, $800 \mu \mathrm{M} 6-\mathrm{OHDA}+200 \mu \mathrm{M}$ ZnAF2DA, $800 \mu \mathrm{M}$ 6-OHDA + 10 mM CaEDTA, an extracellular $\mathrm{Zn}^{2+}$ chelator, $800 \mu \mathrm{M}$ 6-OHDA + 2 mM 6-cyano7-nitroquinoxaline-2,3-dione (CNQX), an a-amino-3-hydroxy-5-methyl-4-isoxazolepropionate (AMPA) receptor antagonist, $800 \mu \mathrm{M}$ 6-OHDA + $50 \mu \mathrm{M}$ HYDROP $^{\text {TM }}$, or $2 \mu \mathrm{M}$ GBR 13069 dihydrochloride (GBR), a dopamine reuptake inhibitor in saline containing $0.1 \%$ ascorbic acid were injected into the right $\mathrm{SNpc}$ via the cannula at the rate of $0.2 \mu \mathrm{l} / \mathrm{min}$ for $5 \mathrm{~min}$. Ten minutes after injection, the injection cannula was carefully and slowly pulled out of the brain in approximately $10 \mathrm{~min}$.

\section{Tyrosine Hydroxylase (Th) Immunostaining}

Two weeks after the surgical operation for the treatment with 6-OHDA, the rats were anesthetized and perfused with ice-cold $4 \%$ paraformaldehyde in PBS. The brain was excised from the rats followed by overnight fixation in $4 \%$ paraformaldehyde in PBS at $4^{\circ} \mathrm{C}$. Fixed brains were cryopreserved in $30 \%$ sucrose in PBS for 2 day and frozen in Tissue-Tek Optimal Cutting Temperature embedding medium. Coronal slices $(30 \mu \mathrm{m})$ of the brains were prepared in a cryostat at $-20^{\circ} \mathrm{C}$, picked up on slides, and adhered for 30 min at room temperature. For TH immunostaining, the slides were incubated in blocking solution (3\% BSA, $0.1 \%$ Triton $\mathrm{X}-100$ in PBS) for $1 \mathrm{~h}$ and rinsed with PBS for $5 \mathrm{~min}$ followed by overnight incubating in anti-tyrosine hydroxylase antibody (Abcam) at $4^{\circ} \mathrm{C}$. The slides were rinsed with PBS for 5 min and incubated in blocking buffer containing Alexa Fluor 633 goat anti-rabbit secondary antibody (ThermoFisher) for $3 \mathrm{~h}$ at room temperature. The slides were bathed in PBS for 5 min six times, mounted with Prolong Gold antifade reagent, and placed at $4^{\circ} \mathrm{C}$ or $24 \mathrm{~h}$. Alexa Fluor 633 fluorescence was observed in the SNpc using a confocal laser-scanning microscopic system.

\section{In Vitro Dynamics Of Intracellular Zn}

Rats were anesthetized with chloral hydrate $(400 \mathrm{mg} / \mathrm{kg})$ and decapitated. The brain was quickly excised and bathed in ice-cold choline-Ringer containing $124 \mathrm{mM}$ choline chloride, $2.5 \mathrm{mM} \mathrm{KCl}, 2.5 \mathrm{mM} \mathrm{MgCl}_{2}$, $1.25 \mathrm{mM} \mathrm{NaH}_{2} \mathrm{PO}_{4}, 0.5 \mathrm{mM} \mathrm{CaCl}_{2}, 26 \mathrm{mM} \mathrm{NaHCO}_{3}$, and $10 \mathrm{mM}$ glucose (pH 7.3) to inhibit excessive neuronal excitation. Horizontal slices $(400 \mu \mathrm{m})$ of the brains were prepared in an ice-cold choline-Ringer 
solution in a vibratome ZERO-1 (Dosaka Kyoto, Japan) and then bathed in an ice-cold choline-Ringer solution. All solutions used in the experiments were continuously bubbled with $95 \% \mathrm{O}_{2}$ and $5 \% \mathrm{CO}_{2}$.

Brain slices were then immersed in $10 \mu \mathrm{M}$ ZnAF-2DA in Ringer solution for $30 \mathrm{~min}$, rinsed in cholineRinger solution for $20 \mathrm{~min}$, placed in a chamber filled with $800 \mu \mathrm{M}$ 6-OHDA or $800 \mu \mathrm{M} 6-\mathrm{OHDA}+10 \mu \mathrm{M}$ $\mathrm{CNQX}$ in Ringer solution containing $10 \mathrm{nM} \mathrm{ZnCl}_{2}$ for $10 \mathrm{~min}$, rinsed in choline-Ringer solution for $15 \mathrm{~min}$, and transferred to a recording chamber filled with Ringer solution. Intracellular ZnAF-2 fluorescence (laser, $488.4 \mathrm{~nm}$; emission, 500-550 nm) was observed in the SNpc with a confocal laser-scanning microscopic system. In another experiment, brain slices loaded with ZnAF-2DA were placed in a chamber filled with $800 \mu \mathrm{M} \mathrm{H}_{2} \mathrm{O}_{2}$ or $800 \mu \mathrm{M} \mathrm{H}_{2} \mathrm{O}_{2}+10 \mu \mathrm{M} \mathrm{CNQX}$ in Ringer solution containing $10 \mathrm{nM} \mathrm{ZnCl}_{2}$ for 10 min and treated in the same manner.

\section{In Vivo Imaging Of Intracellular Ho}

The rats anesthetized with chloral hydrate were treated as described above. Injection cannulae (internal diameter, $0.15 \mathrm{~mm}$; outer diameter, $0.35 \mathrm{~mm}$ ) were carefully and slowly inserted into the both sides of the SNpc (5.3 mm posterior to the bregma, $2.0 \mathrm{~mm}$ lateral, $7.0 \mathrm{~mm}$ inferior to the dura) to prevent cellular damages. Thirty minutes after the surgical operation, $800 \mu \mathrm{M} 6-\mathrm{OHDA}$ or $800 \mu \mathrm{M} 6-\mathrm{OHDA}+2 \mu \mathrm{M}$ GBR in saline containing $0.1 \%$ ascorbic acid and $\operatorname{HYDROP}^{\mathrm{TM}}(50 \mu \mathrm{M})$, were bilaterally injected into the SNpc via cannulae at the rate of $0.2 \mu \mathrm{l} / \mathrm{min}$ for $5 \mathrm{~min}$. Ten minutes later, the injection cannulae were slowly moved from the brain in approximately $3 \mathrm{~min}$ and the rats were decapitated. The brain was quickly excised from the rats and brain slices were prepared in the same manner. The brain slices were transferred to a recording chamber filled with Ringer solution. Intracellular HYDROP fluorescence was observed in the SNpc with a confocal laser-scanning microscopic system.

\section{In Vivo Microdialysis}

The rats anesthetized with chloral hydrate were individually placed in a stereotaxic apparatus in the same manner. The skull was exposed, a burr hole was drilled, and a microdialysis probe (1-mm membrane, Eicom, Kyoto) was carefully and slowly inserted into the right SNpc (5.3 $\mathrm{mm}$ posterior to the bregma, 2.0 $\mathrm{mm}$ lateral, $7.3 \mathrm{~mm}$ inferior to the dura) of anesthetized rats. The SNpc was preperfused with ACSF (127 $\mathrm{mM} \mathrm{NaCl}, 2.5 \mathrm{mM} \mathrm{KCl}, 1.3 \mathrm{mM} \mathrm{CaCl}_{2}, 0.9 \mathrm{mM} \mathrm{MgCl}_{2}, 1.2 \mathrm{mM} \mathrm{Na}_{2} \mathrm{HPO}_{4}, 21 \mathrm{mM} \mathrm{NaHCO}_{3}$ and $3.4 \mathrm{mM}$ Dglucose, $\mathrm{pH} 7.3$ ) at $2.0 \mu \mathrm{l} / \mathrm{min}$ for $180 \mathrm{~min}$ to stabilize the perfusing area, perfused with ACSF for $60 \mathrm{~min}$ in the same manner to determine the basal concentration of glutamate, and then perfused with ACSF, 800 $\mu \mathrm{M} \mathrm{H}_{2} \mathrm{O}_{2}$ in ACSF, $50 \mu \mathrm{M}$ ACA in ACSF, or $800 \mu \mathrm{M} \mathrm{H}_{2} \mathrm{O}_{2}+50 \mu \mathrm{M}$ ACA in ACSF for 60 min.

The perfusate was collected for every $15 \mathrm{~min}$. The perfusate samples $(15 \mu \mathrm{l})$ were analyzed for determining glutamate content by high-performance liquid chromatography (HPLC) [column, CAPCELL PAK C18 UG120A (1 mm x $150 \mathrm{~mm}$ ) (Shiseido Co Ltd, Tokyo, Japan); mobile phase, $0.1 \mathrm{M}$ potassium dihydrogen phosphate, $0.1 \mathrm{M}$ di-sodium hydrogen phosphate, 10\% acetonitrile, $0.5 \mathrm{mM}$ EDTA-2Na, $3 \%$ 
tetrahydrofuran, $\mathrm{pH}$ 6.0] using the pre-column derivatization technique with o-phthaldialdehyde and a fluorescence detector (NANOSPACE SI-2, Shiseido Co Ltd). The basal level of glutamate and the levels during perfusion with $\mathrm{H}_{2} \mathrm{O}_{2}$ were averaged.

\section{Data analysis}

The differences between treatments were assessed by one-way ANOVA followed by post hoc testing using the Tukey's test (the statistical software, GraphPad Prism 5). A value of $p<0.05$ was considered significant. Statistical analysis of the data (means \pm standard error) is described in each figure legend.

\section{Results}

\section{Intracellular $\mathrm{Zn}^{2+}$ dysregulation induced by 6-OHDA causes neurodegeneration}

Brain slices were incubated for 10 min with 6-OHDA in ACSF containing $10 \mathrm{nM} \mathrm{Zn}^{2+}$, an estimated basal concentration of extracellular $\mathrm{Zn}^{2+}$ [17], 6-OHDA rapidly increased intracellular $\mathrm{Zn}^{2+}$ in the SNpc. The increase in intracellular $\mathrm{Zn}^{2+}$ was preferentially observed in the $\mathrm{SNpc}$, while the increase was blocked in the presence of an AMPA receptor antagonist (CNQX) (Fig. 1) in agreement with the case of incubation with a high dose of 6-OHDA (8 $\mathrm{mM})$ reported previously [18].

Turning behavior in response to apomorphine, an index of movement disorder in 6-OHDA-induced PD in rats, was not observed at all after injection of 6-OHDA $(0.8 \mathrm{mM})$ into the SNpc in disagreement with the case of the high dose ( $8 \mathrm{mM})$ [18]. Nigral dopaminergic degeneration induced by a low dose of 6-OHDA $(0.8 \mathrm{mM})$ was determined by $\mathrm{TH}$ immunostaining. Staining intensity was drastically reduced in the ipsilateral SNpc, while the reduction was completely rescued by co-injection of ZnAF-2DA, as an intracellular $\mathrm{Zn}^{2+}$ chelator, as well as CaEDTA and CNQX (Fig. 2), in comparison with the partial rescue effect of ZnAF-2DA on the high dose of 6-OHDA [18], indicating that 6-OHDA-induced influx of extracellular $\mathrm{Zn}^{2+}$ via AMPA receptor activation causes nigral dopaminergic degeneration.

\section{Intracellular $\mathrm{H}_{2} \mathrm{O}_{2}$ produced by 6-OHDA induces extracellular glutamate accumulation via TRPM2 channel activation}

We examined whether 6-OHDA taken up through dopamine transporters produces $\mathrm{H}_{2} \mathrm{O}_{2}$, which is retrogradely transported to presynaptic TRPM2 channels on glutamatergic terminals through the plasma membranes of dopaminergic neurons in the SNpc and accumulates glutamate in the extracellular compartment via TRPM2 channel activation followed by intracellular $\mathrm{Zn}^{2+}$ toxicity. When brain slices were bathed in 6-OHDA, intracellular $\mathrm{H}_{2} \mathrm{O}_{2}$ level was rapidly elevated in the $\mathrm{SNpc}$ and the elevation was completely inhibited by GBR (Fig. 3), suggesting that 6-OHDA taken up through dopamine transporters produces $\mathrm{H}_{2} \mathrm{O}_{2}$ in the intercellular compartment of dopaminergic neurons. 
To examine glutamatergic excitation by $\mathrm{H}_{2} \mathrm{O}_{2}$ transported to presynaptic glutamatergic terminals from dopaminergic neurons, the SNpc was perfused with $\mathrm{H}_{2} \mathrm{O}_{2} \cdot \mathrm{H}_{2} \mathrm{O}_{2}$ accumulated glutamate in the extracellular compartment and the accumulation was inhibited in the presence of ACA, a TRPM2 channel blocker (Fig. 4). When brain slices were incubated for 10 min with $\mathrm{H}_{2} \mathrm{O}_{2}$ in place of 6-OHDA, $\mathrm{H}_{2} \mathrm{O}_{2}$ also rapidly increased intracellular $\mathrm{Zn}^{2+}$ in the SNpc. The increase in intracellular $\mathrm{Zn}^{2+}$ was preferentially observed in the SNpc, while the increase was blocked in the presence CNQX (Fig. 5). We did not determine extracellular glutamate concentration during perfusion with 6-OHDA because the presence of 6-OHDA in the perfusate disturbs the measurement [18].

\section{Is nigral dopaminergic degeneration linked with retrograde transport to glutamatergic terminals of intracellular $\mathrm{H}_{2} \mathrm{O}_{2}$ produced by 6-OHDA?}

Nigral dopaminergic degeneration induced by $\mathrm{H}_{2} \mathrm{O}_{2}$ in place of 6-OHDA was determined by $\mathrm{TH}$ immunostaining. Staining intensity was also significantly reduced in the ipsilateral SNpc, while the reduction was completely rescued by co-injection of ACA (Fig. 6), suggesting the involvement of $\mathrm{H}_{2} \mathrm{O}_{2}$ sensitive TRPM2 channel activation in neurodegeneration.

On the other hand, 6-OHDA-induced dopaminergic degeneration was completely rescued by co-injection of an intracellular $\mathrm{H}_{2} \mathrm{O}_{2}$ scavenger (HYDROP) or a dopamine reuptake inhibitor (GBR) (Fig. 7), suggesting involvement of 6-OHDA-mediated $\mathrm{H}_{2} \mathrm{O}_{2}$ production in the intracellular compartment in neurodegeneration.

\section{Discussion}

Intracellular $\mathrm{Zn}^{2+}$ dysregulation induced by $6-\mathrm{OHDA}$ is linked with dopaminergic degeneration in the SNpc [18]. However, the mechanism of the rapid $\mathrm{Zn}^{2+}$ dysregulation is unknown and it is not proven whether the rapid $\mathrm{Zn}^{2+}$ dysregulation in the intracellular compartment is a trigger for 6-OHDA-induced PD pathogenesis in rats. We postulated that 6-OHDA-induced production of intracellular $\mathrm{H}_{2} \mathrm{O}_{2}$ is closely linked with intracellular $\mathrm{Zn}^{2+}$ dysregulation in the SNpc, which may lead to 6-OHDA-induced PD pathogenesis in rats. To test the postulation, in the present study, we used a low dose of 6-OHDA, which did not cause any movement disorder in response to apomorphine. 6-OHDA significantly caused nigral dopaminergic degeneration, while the neurodegeneration was completely rescued by co-injection of ZnAF-2DA, as an intracellular $\mathrm{Zn}^{2+}$ chelator, as well as CaEDTA and CNQX, in comparison with the partial rescue effect of ZnAF-2DA on the high dose of 6-OHDA reported previously [18], indicating that 6-OHDAinduced intracellular $\mathrm{Zn}^{2+}$ dysregulation via AMPA receptor activation causes nigral dopaminergic degeneration. It has been reported that $\mathrm{Ca}^{2+}$ - and $\mathrm{Zn}^{2+}$-permeable GluR2-lacking AMPA receptor activation in the SNpc is involved in age-related vulnerability of nigral dopaminergic neurons [19].

6-OHDA is readily oxidized and generates a number of ROS, e.g., the superoxide anion radical, the hydroxy radical, singlet oxygen, and $\mathrm{H}_{2} \mathrm{O}_{2}$ in both extracellular and intracellular compartments [7]. We postulated that presynaptic glutamatergic excitation, which innervates nigral dopaminergic neurons, is required for 
the rapid intracellular $\mathrm{Zn}^{2+}$ dysregulation followed by preferential dopaminergic degeneration in the SNpc. We focused on membrane-permeable $\mathrm{H}_{2} \mathrm{O}_{2}$ to prove the postulation, which is an idea that $\mathrm{H}_{2} \mathrm{O}_{2}$ is produced by $6-\mathrm{OHDA}$ taken up through dopamine transporters, retrogradely transported to presynaptic TRPM2 channels from postsynaptic dopaminergic neurons, and activates glutamatergic synapses in the SNpc (Fig. 8). Intracellular $\mathrm{H}_{2} \mathrm{O}_{2}$ level in the SNpc elevated by 6-OHDA was completely inhibited by coinjection of, a dopamine reuptake inhibitor (GBR), suggesting that 6-OHDA taken up through dopamine transporters produces $\mathrm{H}_{2} \mathrm{O}_{2}$ in the intercellular compartment of dopaminergic neurons. Disruption of redox homeostasis is a key phenotype of many neurological disorders including PD. $\mathrm{H}_{2} \mathrm{O}_{2}$ is widely recognized as a mediator and an inducer of oxidative stress. Attention has been focused on the role of lipid hydroperoxides as critical mediators of cell death [20-23]. Although $\mathrm{H}_{2} \mathrm{O}_{2}$ itself can cause nigral dopaminergic degeneration as described below, the degeneration induced by 6-OHDA-produced $\mathrm{H}_{2} \mathrm{O}_{2}$ is completely rescued in the presence of an intracellular $\mathrm{Zn}^{2+}$ chelator (ZnAF-2DA) as described above, indicating that intracellular $\mathrm{Zn}^{2+}$ dysregulation plays a crucial role for nigral dopaminergic degeneration induced by 6-OHDA.

To examine glutamatergic excitation by $\mathrm{H}_{2} \mathrm{O}_{2}$ transported retrogradely (Fig. 8), the SNpc was perfused with $\mathrm{H}_{2} \mathrm{O}_{2} \cdot \mathrm{H}_{2} \mathrm{O}_{2}$ accumulated glutamate in the extracellular compartment and the accumulation was inhibited in the presence of a TRPM2 channel blocker (ACA). In addition to 6-OHDA, $\mathrm{H}_{2} \mathrm{O}_{2}$ also rapidly increased intracellular $\mathrm{Zn}^{2+}$ in the SNpc via AMPA receptor activation followed nigral dopaminergic degeneration that is linked with $\mathrm{H}_{2} \mathrm{O}_{2}$-sensitive TRPM2 channel activation. It has been reported that neuron-specific TRPM2 cation channels may contribute to the pathophysiology of neurological disorders, e.g., cerebral ischemia and oxygen-glucose deprivation [14, 24-27]. The increase in TRPM2 channel expression enhances the susceptibility to ROS-induced cell death in human neuroblastoma SH-SY5Y cells, a dopaminergic neuronal cell line [28]. The expression of TRPM2 cation channels is increased in substantia nigra of 1-methyl-4-phenyl-1,2,3,6-tetrahydropyridine (MPTP)-induced PD mouse model and also PD patients [29].

Furthermore, 6-OHDA-induced dopaminergic degeneration was completely rescued by co-injection of an intracellular $\mathrm{H}_{2} \mathrm{O}_{2}$ scavenger (HYDROP) or a dopamine reuptake inhibitor (GBR), suggesting that 6-OHDAmediated $\mathrm{H}_{2} \mathrm{O}_{2}$ production in the intracellular compartment is much more critical for nigral neurodegeneration than in the extracellular compartment. 6-OHDA has been shown to produce endogenously in patients suffering from PD [30,31]. In addition to 6-OHDA, therefore, it is estimated that dopamine-mediated $\mathrm{H}_{2} \mathrm{O}_{2}$ production in the intracellular compartment may be a key trigger for PD pathogenesis [32,33].

In conclusion, the present study indicates that $\mathrm{H}_{2} \mathrm{O}_{2}$ is produced by 6-OHDA taken up through dopamine transporters in the $\mathrm{SNpc}$, is retrogradely transported to presynaptic glutamatergic terminals, activates TRPM2 channels, accumulates glutamate in the extracellular compartment, and rapidly induces intracellular $\mathrm{Zn}^{2+}$ dysregulation via AMPA receptor activation, resulting in nigral dopaminergic 
degeneration (Fig. 8). It is likely that intracellular $\mathrm{H}_{2} \mathrm{O}_{2}$, but not extracellular $\mathrm{H}_{2} \mathrm{O}_{2}$, is a key trigger in nigral dopaminergic degeneration via intracellular $\mathrm{Zn}^{2+}$ dysregulation and that intracellular $\mathrm{Zn}^{2+}$ dysregulation induced by dopamine dynamics is involved in PD pathogenesis.

\section{Declarations}

Funding statement: The authors received no funding in the present paper. The present paper contains non-financial interests.

Author contributions: Conceptualization; Atsushi Takeda: Data curation; Haruna Tamano: Formal

analysis; Ryusuke Nishio: Investigation; Ryusuke Nishio, Hiroki, Morioka, Azusa Takeuchi, Nana Saeki, Ryo Furuhata, Takato Chinenn: Methodology; Atsushi Takeda: Project administration; Atsushi Takeda: Resources; Atsushi Takeda: Software; Ryusuke Nishio: Supervision; Haruna Tamano: Validation; Atsushi Takeda: Roles/Writing - original draft; Ryusuke Nishio: Writing_review \& editing; Atsushi Takeda Availability of data and material: Not applicable Compliance with ethical standards: The authors declare that they have no conflict of interest. The Ethics Committee for Experimental Animals has permitted the present study in the University of Shizuoka. There is no informed consent because the present study does not deal with human study.

Consent to participate: The present paper has been approved by all named authors.

Consent for Publication: The present paper, which is original, has not been published before and is not currently being considered for publication elsewhere.

Acknowledgments: Not applicable

\section{References}

1. Kouli A, Torsney KM, Kuan WL, Thomas BS, Greenland JC (2018) In: Parkinson's Disease: Pathogenesis and Clinical Aspects [Internet]. Brisbane (AU): Codon Publications, pp 3-26

2. de Lau LM, Breteler MM (2006) Epidemiology of Parkinson's disease. Lancet Neurol 5:525-535

3. Zhai S, Tanimura A, Graves SM, Shen W, Surmeier DJ (2017) Striatal synapses, circuits, and Parkinson's disease. Curr Opin Neurobiol 48:9-16

4. Fahn S, Cohen G (1992) The oxidant stress hypothesis in Parkinson's disease: Evidence supporting it. Ann Neurol 32:804-812

5. Jackson-Lewis V, Blesa J, Przedborski S (2012) Animal models of Parkinson's disease. Parkinsonism Relat Disord S183-185

6. Rodriguez-Pallares J, Parga JA, Joglar B, Guerra MJ, Labandeira-Garcia JL (2009) The Mitochondrial ATP-Sensitive Potassium Channel Blocker 5-Hydroxydecanoate Inhibits Toxicity of 6-

Hydroxydopamine on Dopaminergic Neurons. Neurotox Res 15:82-95

7. Jonsson G (1980) Chemical neurotoxins as denervation tools in neurobiology. Annu Rev Neurosci 3:169-187 
8. Tamano H, Morioka H, Nishio R, Takeuchi A, Takeda A (2019) Blockade of rapid influx of extracellular $\mathrm{Zn}^{2+}$ into nigral dopaminergic neurons overcomes Paraquat-induced Parkinson's disease in rats. Mol Neurobiol 56:4539-4548

9. Tamano H, Nishio R, Morioka H, Furuhata R, Komata Y, Takeda A (2019) Paraquat as an environmental risk factor in Parkinson's disease accelerates age-related degeneration via rapid influx of extracellular $\mathrm{Zn}^{2+}$ into nigral dopaminergic neurons. Mol Neurobiol 56:7789-7799

10. Fujita T (2002) Formation and removal of reactive oxygen species, lipid peroxides and free radicals, and their biological effects. Yakugaku Zasshi 22:203-218

11. Fisher AB (2009) Redox Signaling Across Cell Membranes. Antioxid Redox Signal 11:1349-1356

12. Hara Y, Wakamori M, Ishii M, Maeno E, Nishida M, Yoshida T, Yamada H, Shimizu S, Mori E, Kudoh J, Shimizu N, Kurose H, Okada Y, Imoto K, Mori Y (2002) LTRPC2 Ca2+-permeable channel activated by changes in redox status confers susceptibility to cell death. Mol Cell 9:163-173

13. Sun Y, Sukumaran P, Selvaraj S, Cilz NI, Schaar A, Lei S, Singh BB (2018) TRPM2 Promotes Neurotoxin MPP ${ }^{+} / M_{P T P}-I n d u c e d$ Cell Death. Mol Neurobiol 55:409-420

14. Turlova E, Feng ZP, Sun HS (2018) The role of TRPM2 channels in neurons, glial cells and the bloodbrain barrier in cerebral ischemia and hypoxia. Acta Pharmacol Sin 39:713-721

15. Hirano T, Kikuchi K, Urano Y, Nagano T (2002) Improvement and biological applications of fluorescent probes for zinc, ZnAFs. J Am Chem Soc 124:6555-6562

16. Abo M, Urano Y, Hanaoka K, Terai T, Komatsu T, Nagano T (2011) Development of a highly sensitive fluorescence probe for hydrogen peroxide. J Am Chem Soc 133:10629-10637

17. Frederickson CJ, Giblin LJ, Krezel A, McAdoo DJ, Muelle RN, Zeng Y, Balaji RV, Masalha R et al (2006) Concentrations of extracellular free zinc ( $\mathrm{pZn}) \mathrm{e}$ in the central nervous system dur- ing simple anesthetization, ischemia and reperfusion. Exp Neurol 198:285-293

18. Tamano H, Nishio R, Morioka H, Takeda A (2019) Extracellular $\mathrm{Zn}^{2+}$ influx into nigral dopaminergic neurons plays a key role for pathogenesis of 6-hydroxydopamine-induced Parkinson's disease in rats. Mol Neurobiol 56:435-443

19. Nakajima S, Saeki N, Tamano H, Nishio R, Katahira M, Takeuchi A, Takeda A (2021) Age-related vulnerability to nigral dopaminergic degeneration in rats via $\mathrm{Zn}^{2+}$-permeable GluR2-lacking AMPA receptor activation. NeuroToxicol 83:69-76

20. Pratico D, Zhukareva V, Yao Y, Uryu K, Funk CD, Lawson JA, Trojanowski JQ, Lee VM (2004) 12/15lipoxygenase is increased in Alzheimer's disease: possible involvement in brain oxidative stress. Am J Pathol 164:1655e1662

21. Galasko DR, Peskind E, Clark CM, Quinn JF, Ringman JM, Jicha GA, Cotman C, Cottrell B, Montine TJ, Thomas RG, Aisen P, S. Alzheimer's Disease Cooperative (2012) Antioxidants for Alzheimer disease: a randomized clinical trial with cerebrospinal fluid biomarker measures. Arch Neurol 69: 836e841

22. Persson T, Popescu BO, Cedazo-Minguez A (2014) Oxidative stress in Alzheimer's disease: why did antioxidant therapy fail? Oxid Med Cell Longev 2014: 427318 
23. Gaschler MM, Stockwell BR (2017) Lipid peroxidation in cell death. Biochem Biophys Res Commun 482:419-425

24. Aarts MM, Tymianski M (2005) TRPMs and neuronal cell death. Pflugers Arch 451:243-249

25. Sita G, Hrelia P, Graziosi A, Ravegnini G, Morroni F (2018) TRPM2 in the Brain: Role in Health and Disease. Cells 7:82

26. Akyuva Y, Nazıroğlu M (2020) Resveratrol attenuates hypoxia-induced neuronal cell death, inflammation and mitochondrial oxidative stress by modulation of TRPM2 channel. Sci Rep 10:6449

27. Osmanlıoğlu H, Yıldııım MK, Akyuva Y, Yıldızhan K, Nazıroğlu M (2020) Morphine Induces Apoptosis, Inflammation, and Mitochondrial Oxidative Stress via Activation of TRPM2 Channel and Nitric Oxide Signaling Pathways in the Hippocampus. Mol Neurobiol 57:3376-3389

28. An X, Fu Z, Mai C, Wang W, Wei L, Li D, Li C, Jiang LH (2019) Increasing the TRPM2 Channel Expression in Human Neuroblastoma SH-SY5Y Cells Augments the Susceptibility to ROS-Induced Cell Death. Cells 8:28

29. Sun Y, Sukumaran P, Selvaraj S, Cilz NI, Schaar A, Lei S, Singh BB (2018) TRPM2 Promotes Neurotoxin MPP ${ }^{+} / M_{P} T P-I n d u c e d$ Cell Death. Mol Neurobiol 55:409-420

30. Andrew R, Watson DG, Best SA, Midgley JM, Wenlong H, Petty RK (1993) The determination of hydroxydopamines and other trace amines in the urine of parkinsonian patients and normal controls. Neurochem Res 18:1175-1177

31. Jellinger K, Linert L, Kienzl E, Herlinger E, Youdim MB (1995) Chemical evidence for 6hydroxydopamine to be an endogenous toxic factor in the pathogenesis of Parkinson's disease. $J$ Neural Transm Suppl 46:297-314

32. Miyazaki I, Asanuma M (2008) Dopaminergic neuron-specific oxidative stress caused by dopamine itself. Acta Med Okayama 62:141-150

33. Yamato M, Kudo W, Shiba T, Yamada KI, Watanabe T, Utsumi H (2010) Determination of reactive oxygen species associated with the degeneration of dopaminergic neurons during dopamine metabolism. Free Radic Res 44:249-257

\section{Figures}



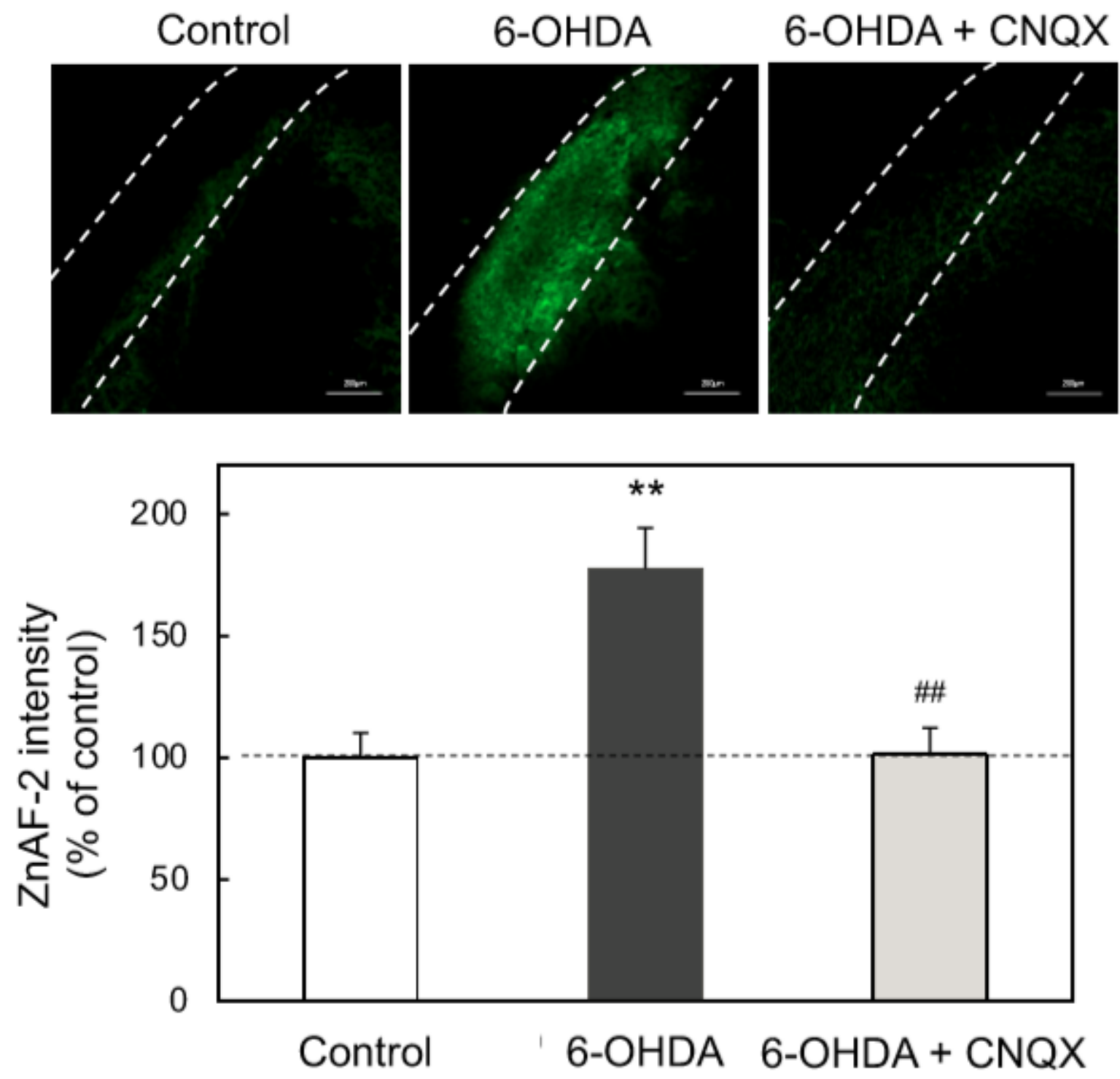

Figure 1

6-OHDA increases intracellular Zn2+ concentration in the SNpc in vitro Brain slices loaded with ZnAF-2DA were bathed in Ringer containing $10 \mathrm{nM} \mathrm{ZnCl} 2$ (control, $n=6), 800 \mu \mathrm{M}$ 6-OHDA ( $n=5)$ or $800 \mu \mathrm{M}$ 6-OHDA + $10 \mu \mathrm{M}$ CNQX ( $\mathrm{n}=4)$. Ten minutes later. intracellular ZnAF-2 fluorescence was determined in the SNpc surrounded by the white dotted line (upper). Each bar and line represent the ratio of ZnAF-2 fluorescence to the control ZnAF-2 fluorescence, which was expressed as $100 \%$ (lower). **, $p<0.01$, vs. control, \#\#, p $<0.01$, vs. 6-OHDA (Tukey's test). 


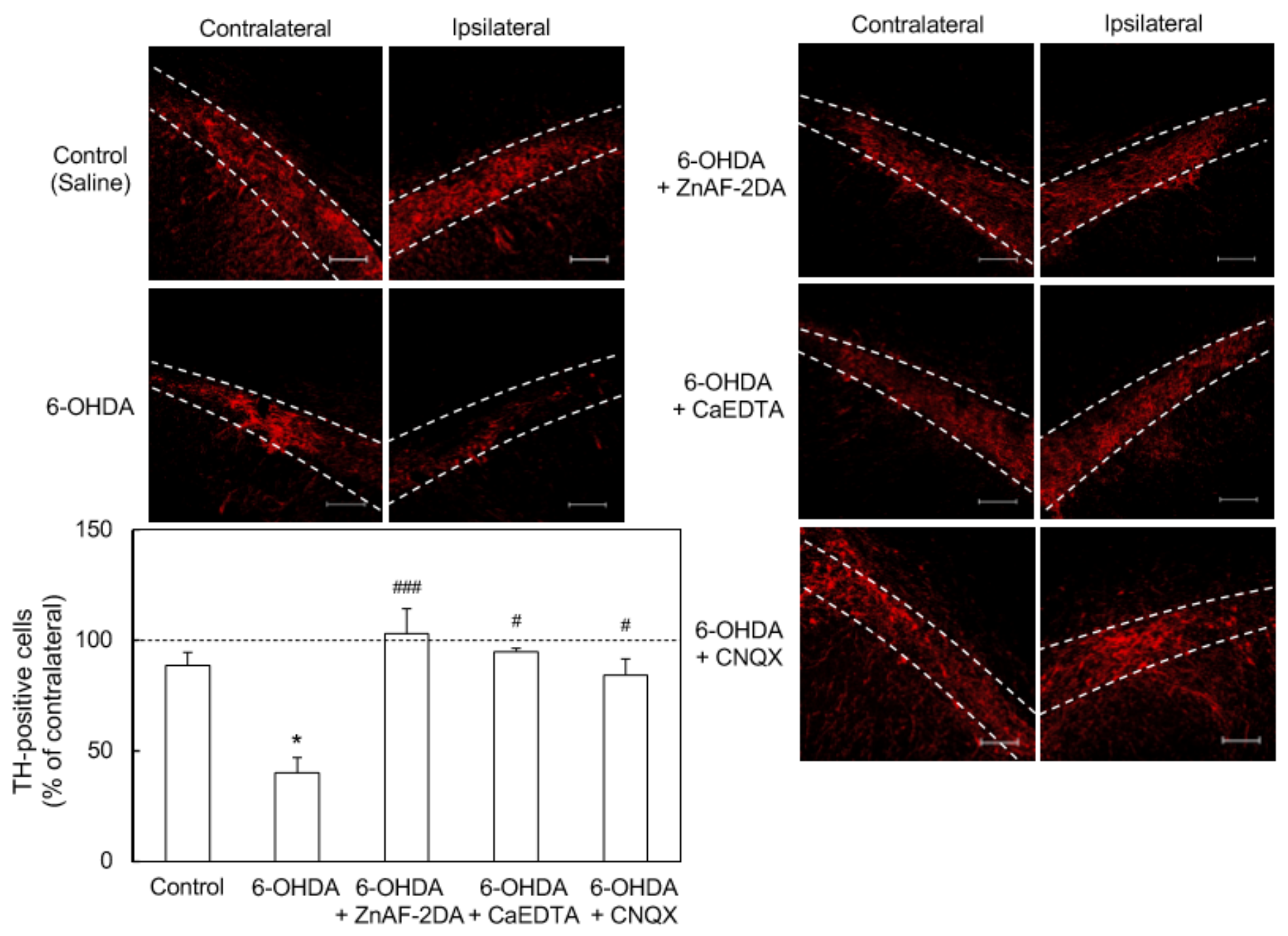

Figure 2

Neuronal loss in the SNpc after injection of 6-OHDA into the SNpc. Saline containing $0.1 \%$ ascorbic acid $(n=6), 800 \mu \mathrm{M}$ 6-OHDA in saline containing 0.1\% ascorbic acid ( $n=8), 800 \mu \mathrm{M} 6-0 H D A+200 \mu \mathrm{ZnAF}-$ 2DA in saline containing $0.1 \%$ ascorbic acid $(n=6), 800 \mu \mathrm{M} 6-\mathrm{OHDA}+10 \mathrm{mM}$ CaEDTA in saline containing $0.1 \%$ ascorbic acid $(n=4)$, or $800 \mu \mathrm{M}$ 6-OHDA + 2 mM CNQX in saline containing $0.1 \%$ ascorbic acid ( $n=8)$ were unilaterally injected into the SNpc. Two weeks later, TH immunostaining with Alexa Fluor 633 fluorescence was determined in the SNpc surrounded by the white dotted line. Each bar and line represent the ratio of Alexa Fluor 633 fluorescence in the ipsilateral SNpc to Alexa Fluor 633 fluorescence in the contralateral SNpc, which was expressed as 100\% (lower-left). * , p < 0.05, vs. control, \#, p<0.05, \#\#\#, p< 0.001, vs. 6-OHDA (Tukey's test). 


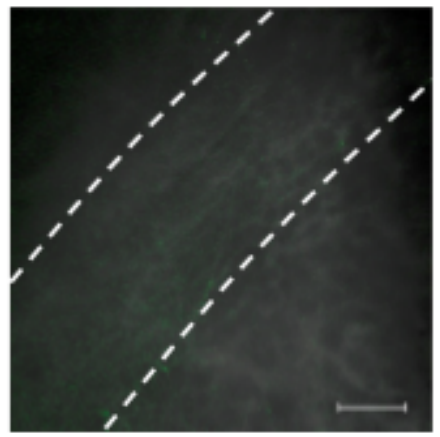

Control

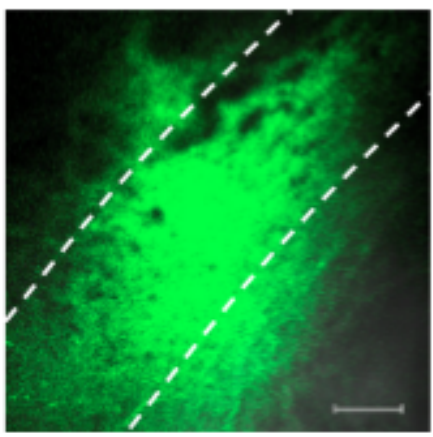

6-OHDA

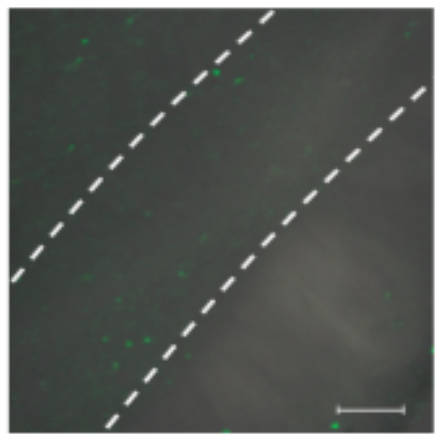

$6-\mathrm{OHDA}+\mathrm{GBR}$

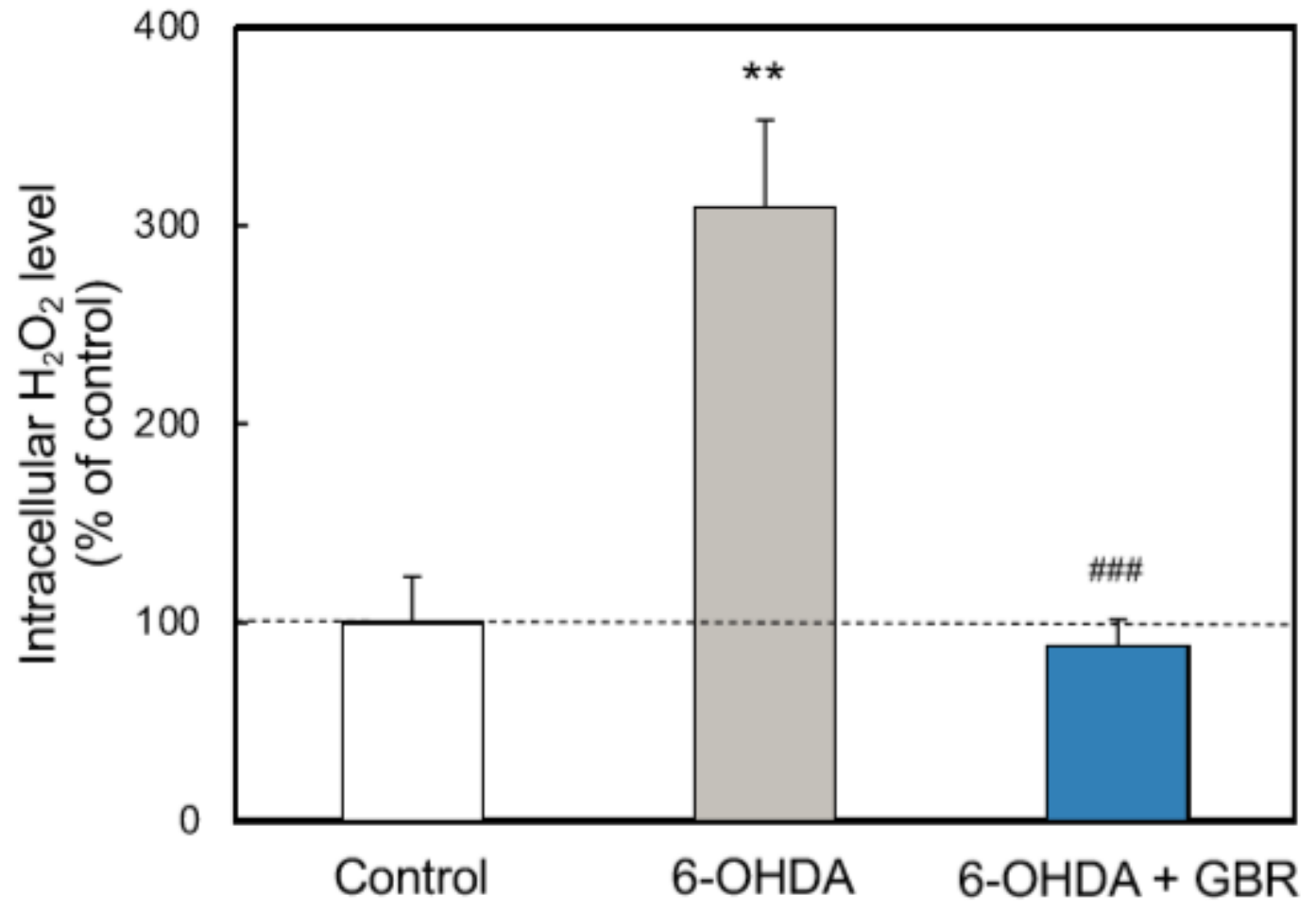

Figure 3

6-OHDA increases intracellular $\mathrm{H} 2 \mathrm{O} 2$ concentration in the SNpc Saline containing $0.1 \%$ ascorbic acid (control, $n=5), 800 \mu \mathrm{M} 6-\mathrm{OHDA}$ in saline containing $0.1 \%$ ascorbic acid $(n=3)$, or $800 \mu \mathrm{M}$ 6-OHDA+2 $\mu \mathrm{M}$ GBR in saline containing $0.1 \%$ ascorbic acid $(n=4)$, which contain Hydrop $(50 \mu M)$, were bilaterally injected into the SNpc. Ten minutes after injection, intracellular Hydrop fluorescence was determined in the SNpc surrounded by the white dotted line (upper). Each bar and line represent the ratio of Hydrop fluorescence in SNpc to the control Hydrop fluorescence in SNpc, which was expressed as $100 \%$ (lower). $\star *, p<0.01$, vs. control (saline), \#\#\#, p<0.001, vs. 6-OHDA (Tukey's test). 


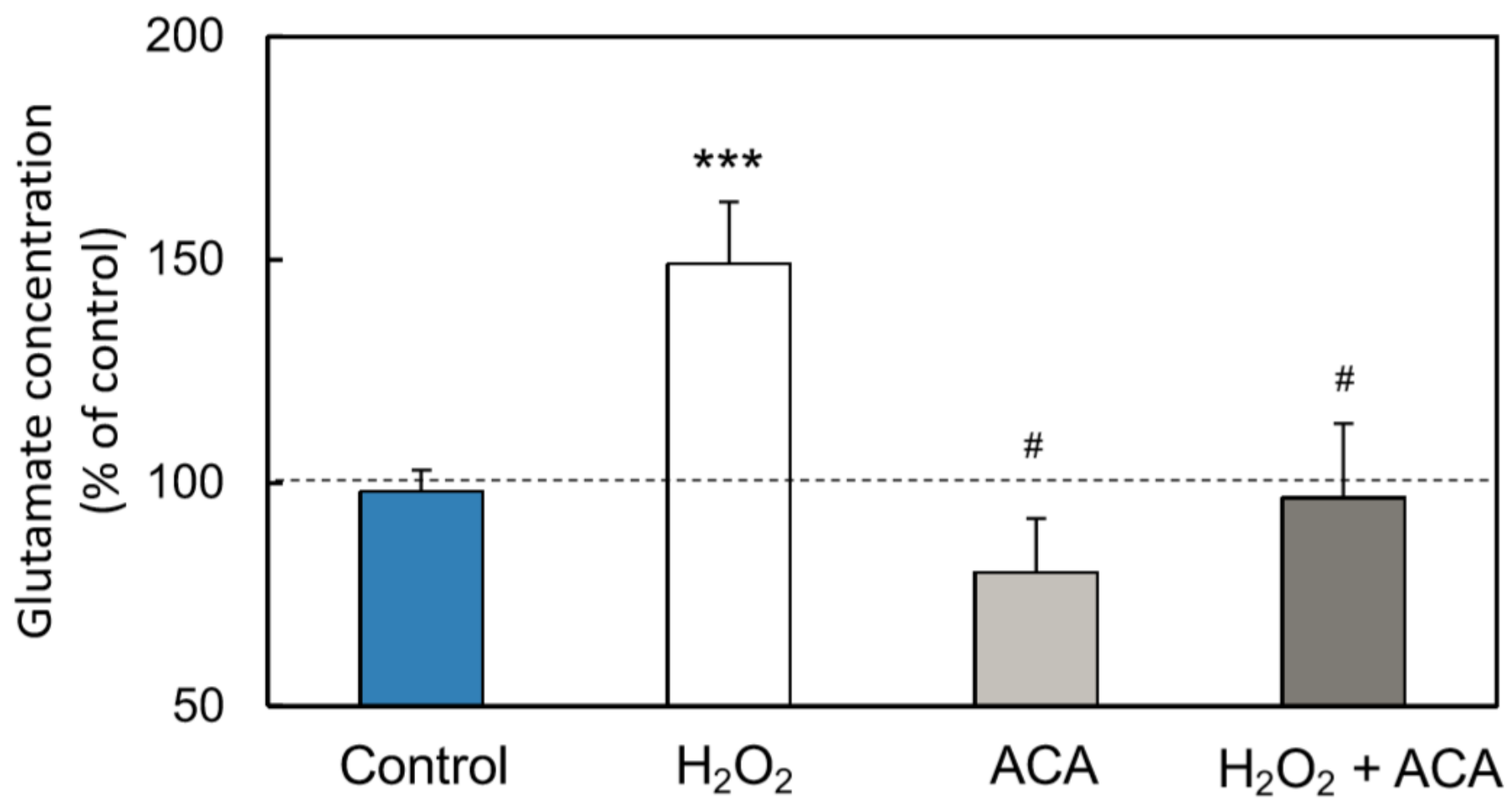

Figure 4

$\mathrm{H} 2 \mathrm{O} 2$ increases extracellular concentrations of glutamate in the SNpc The SNpc was perfused with ACSF $(n=10), 800 \mu \mathrm{M} \mathrm{H} 2 \mathrm{O} 2$ in ACSF ( $n=6), 50 \mu \mathrm{M}$ ACA in ACSF ( $n=4)$, or $800 \mu \mathrm{M} \mathrm{H} 2 \mathrm{O} 2+50 \mu \mathrm{M}$ ACA in ACSF $(n=4)$. Each bar and line represent the ratio of glutamate concentration in the perfusate to the basal glutamate concentration in the perfusate, which was perfused with ACSF. $* \star \star, p<0.001$, vs. the control (ACSF), \#, p < 0.05, vs. H2O2 (Tukey's test) 

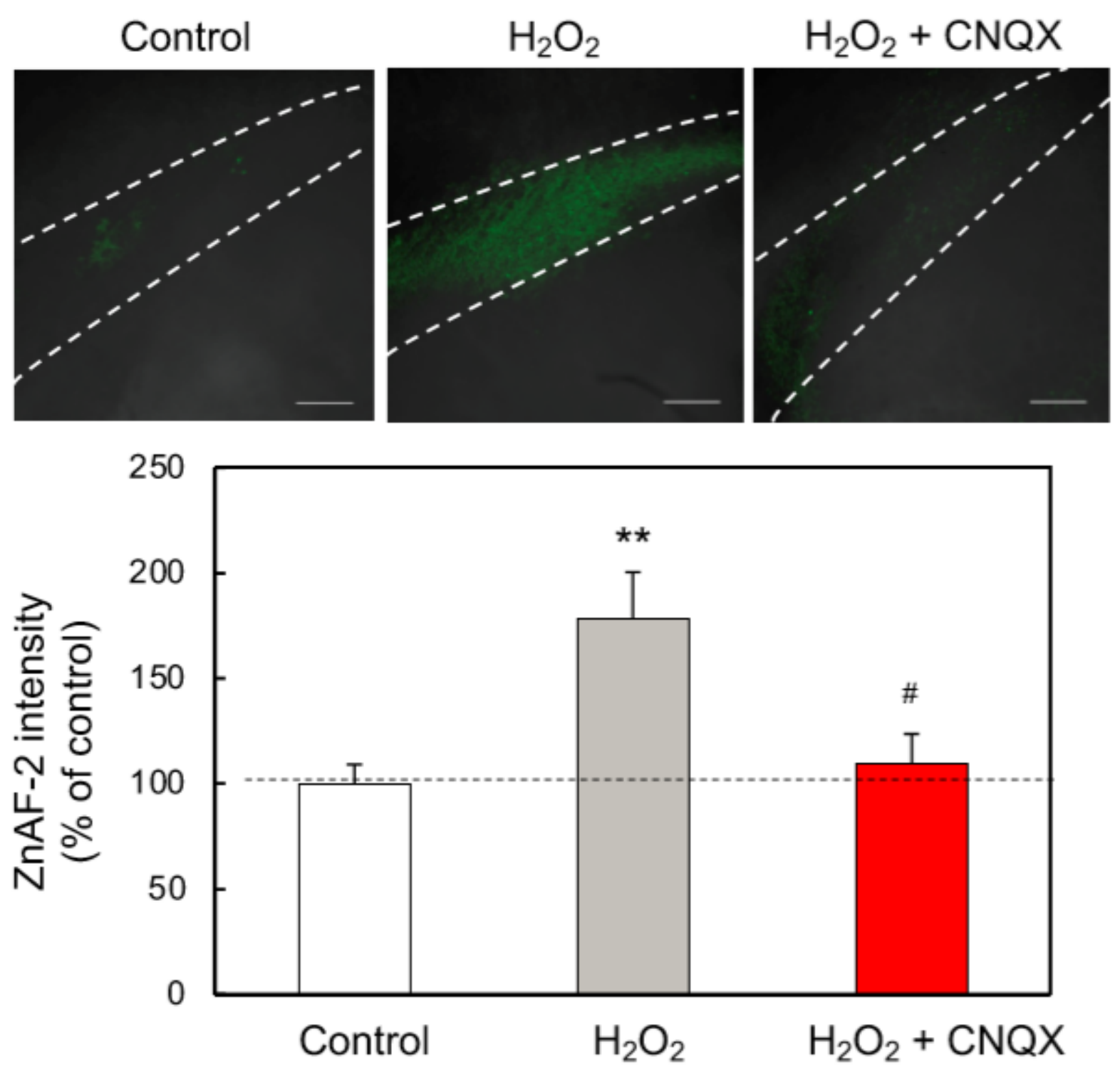

Figure 5

$\mathrm{H} 2 \mathrm{O} 2$ increases intracellular Zn2+ concentration in the SNpc in vitro Brain slices loaded with ZnAF-2DA were bathed in Ringer containing 10nM ZnCl2 (control, $n=10), 800 \mu \mathrm{M} \mathrm{H} 2 \mathrm{O} 2(\mathrm{n}=9)$ or $800 \mu \mathrm{M} \mathrm{H} 2 \mathrm{O} 2+10$ $\mu \mathrm{M}$ CNQX $(n=4)$. Ten minutes later, intracellular ZnAF-2 fluorescence was determined in the SNpc surrounded by the white dotted line (upper). Each bar and line represent the ratio of ZnAF-2 fluorescence to the control ZnAF-2 fluorescence, which was expressed as $100 \%$ (lower). ${ }^{*}, \mathrm{p}<0.01$, vs. control, \#, p $<0.05$, vs. H2O2 (Tukey's test). 


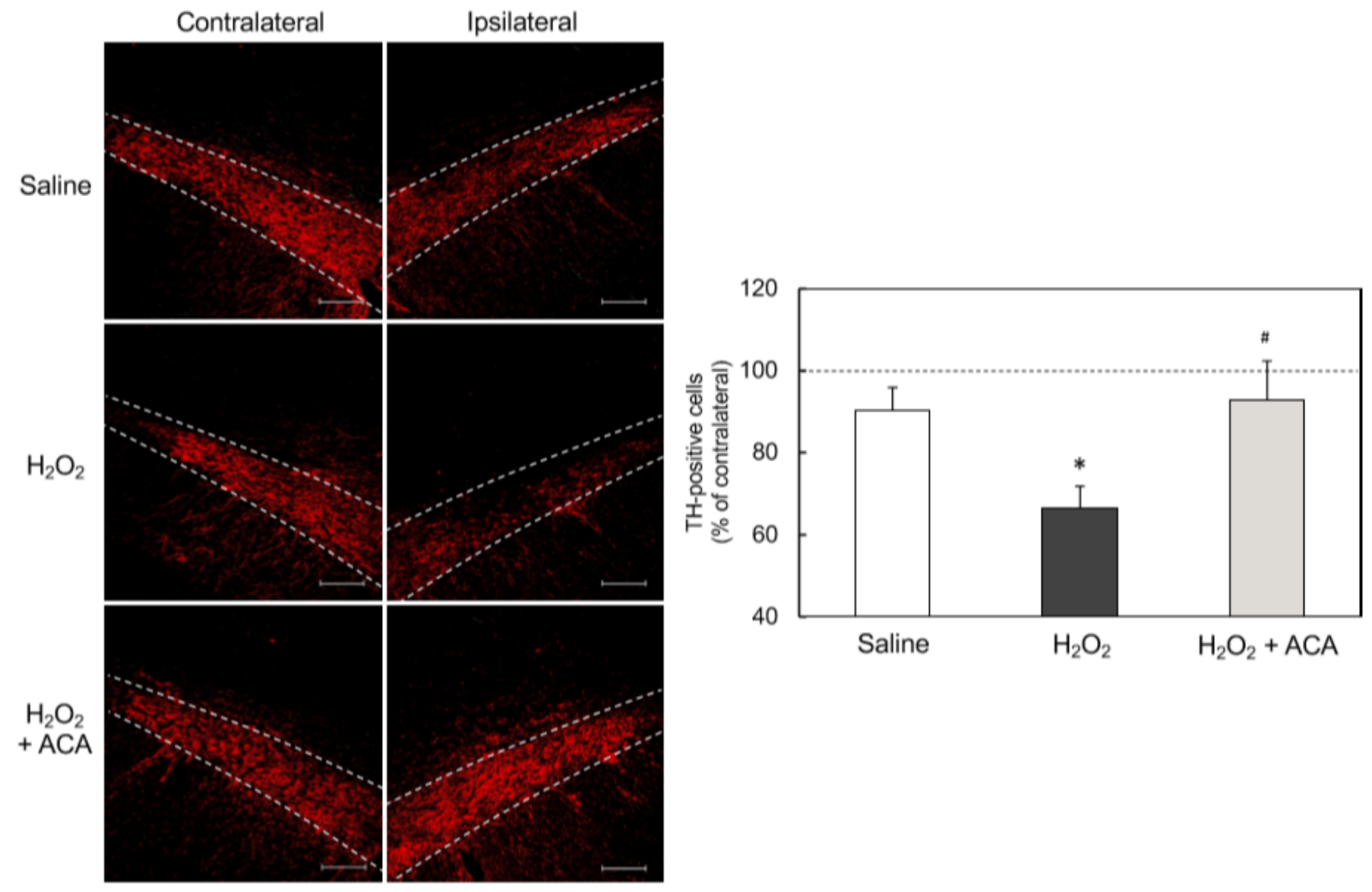

Figure 6

Neuronal loss in the SNpc after injection of H2O2 into the SNpc. Saline (n=7), $800 \mu \mathrm{M} \mathrm{H} 2 \mathrm{O} 2$ in saline $(n=8), 800 \mu \mathrm{M} \mathrm{H} 2 \mathrm{O} 2+50 \mu \mathrm{M}$ ACA in saline $(n=4)$ were unilaterally injected into the SNpc. Two weeks later, TH immunostaining with Alexa Fluor 633 fluorescence was determined in the SNpc surrounded by the white dotted line (left). Each bar and line represent the ratio of Alexa Fluor 633 fluorescence in the ipsilateral SNpc to Alexa Fluor 633 fluorescence in the contralateral SNpc, which was expressed as $100 \%$ (right). *, $p<0.05$, vs. control (saline), \#, $p<0.05$, vs. H2O2 (Tukey's test) 


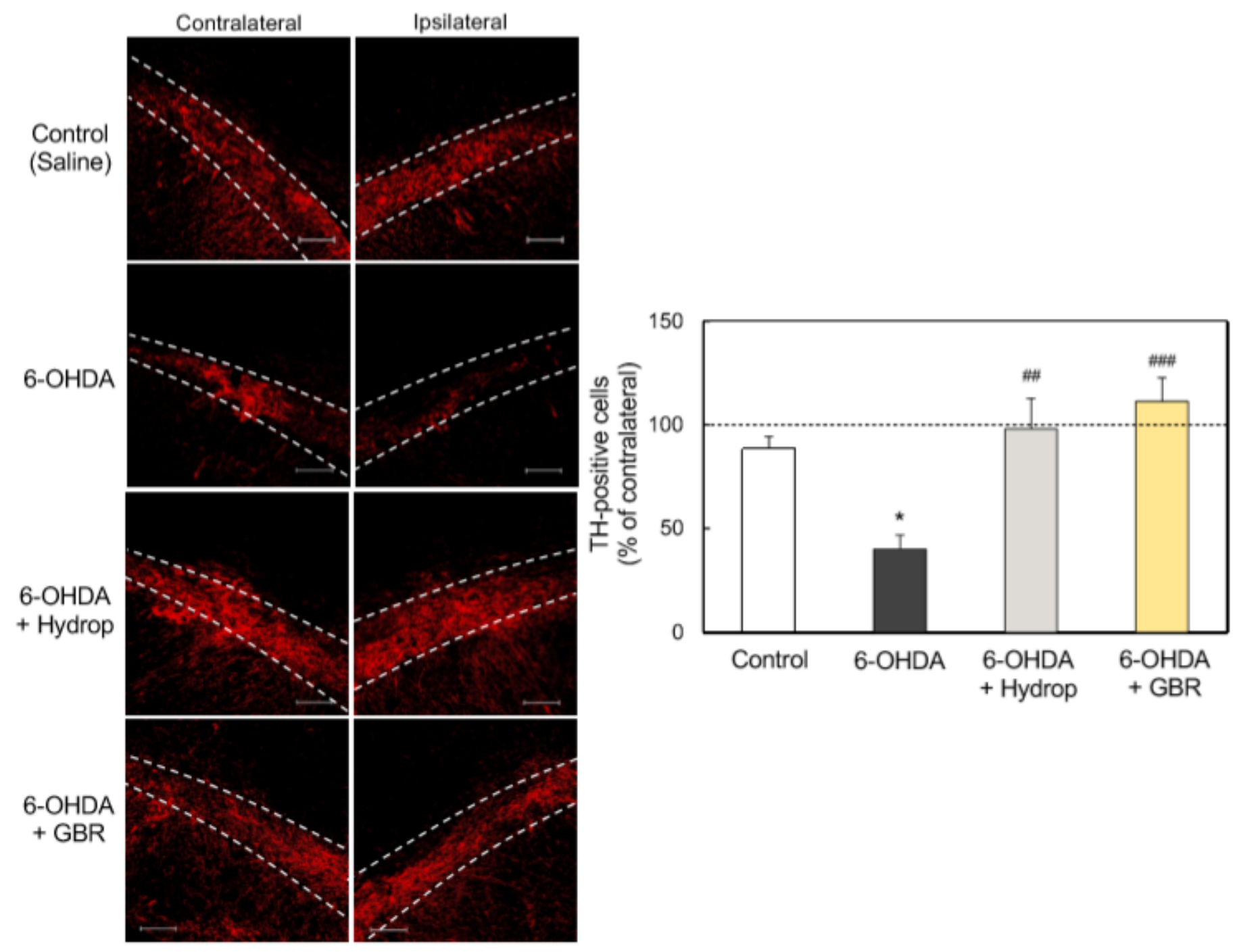

Figure 7

Neuronal loss in the SNpc after injection of 6-OHDA into the SNpc. Saline containing $0.1 \%$ ascorbic acid (control, $n=6$ ), $800 \mu \mathrm{M}$ 6-OHDA in saline containing $0.1 \%$ ascorbic acid $(n=8), 800 \mu \mathrm{M} 6-\mathrm{OHDA}+50 \mu \mathrm{M}$ Hydrop in saline containing $0.1 \%$ ascorbic acid $(n=6)$, or $800 \mu \mathrm{M} 6-\mathrm{OHDA}+2 \mu \mathrm{M}$ GBR in saline containing $0.1 \%$ ascorbic acid $(n=8)$ were unilaterally injected into the SNpc. Two weeks later, TH immunostaining with Alexa Fluor 633 fluorescence was performed in the SNpc surrounded by the white dotted line (left). Each bar and line represent the ratio of Alexa Fluor 633 fluorescence in the ipsilateral SNpc to Alexa Fluor 633 fluorescence in the contralateral SNpc, which was expressed as $100 \%$ (right). ${ }^{*}, p<0.05$, vs. control, $\# \#, p<0.01, \# \# \#, p<0.001$, vs. 6-OHDA (Tukey's test) 


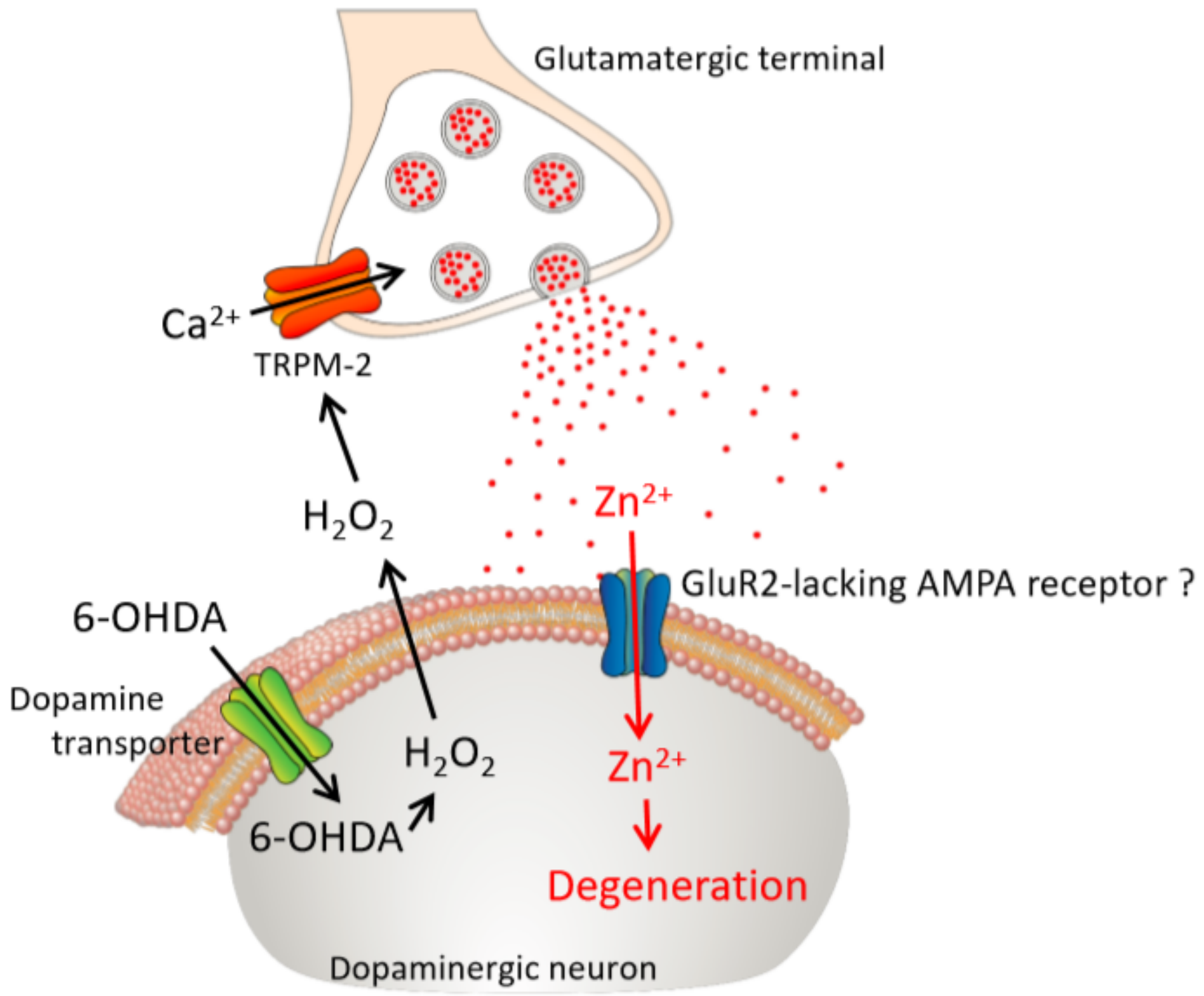

Figure 8

Proposed mechanism on dopaminergic degeneration induced by 6-OHDA-mediated production of intracellular $\mathrm{H} 2 \mathrm{O} 2$ Toxic signaling of $\mathrm{H} 2 \mathrm{O} 2$ produced by 6-OHDA is readily converted into that of $\mathrm{Zn} 2+$, which may pass through GluR2-lacking AMPA receptors. 